\title{
GEOPOLITICAL RISKS AND THE OIL-STOCK NEXUS
}

\section{OVER 1899-2016}

\author{
Nikolaos Antonakakis ${ }^{\mathrm{a}, \mathrm{b}}$ *, Rangan Gupta ${ }^{\mathrm{c}}$, Christos Kollias ${ }^{\mathrm{d}}$, Stephanos Papadamou ${ }^{\mathrm{d}}$ \\ ${ }^{a}$ Webster Vienna Private University; ${ }^{b}$ University of Portsmouth, ${ }^{c}$ University of Pretoria, \\ dUniversity of Thessaly
}

\begin{abstract}
Markets are invariably influenced and affected not only by the usual array of economic and financial factors, but also by uncertainty inducing shocks. Using monthly stock and oil data that spans over a century, this study takes a long historical perspective on whether the time-varying stock-oil covariance, their returns and their variances are affected by geopolitical risk, as encapsulated and quantified by a recently developed index (Caldara and Iacoviello, 2016). The results reveal that geopolitical risk triggers a negative effect, mainly on oil returns and volatility, and to a smaller degree on the covariance between the two markets.

JEL classification: $\mathrm{H} 56, \mathrm{G} 1, \mathrm{G} 15$
\end{abstract}

Key words: Geopolitical Risk; Stock and Oil markets; BEKK-GARCH models

\footnotetext{
${ }^{*}$ Corresponding author. Email: nikolaos.antonakakis@webster.ac.at, tel: +43 12699293 4354; Email: nikolaos.antonakakis@port.ac.uk, tel: +44 (0)23 9284 4261, fax: +44 (0)239284 4037.
} 


\section{Introduction}

Invariably, markets echo and reverberate major political changes and events. Ample empirical evidence shows that economic agents and markets react to exogenous incidents - anthropogenic or natural, adjust and adapt to the broader political environment as it evolves and changes (inter alia: Pástor and Veronesi, 2013; Kaplanski and Levy, 2010; Berkman et al. 2011; Hudson and Uruhart, 2015; Dimic et al. 2016). In particular, the characteristics and the dynamics of the domestic as well as the international political environment significantly affect the economy, markets and market agents' sentiment and behavior (inter alia: Wolfers and Zitzewitz, 2009; Bialkowski et al. 2008; Fielding, 2003; Gaibulloev and Sandler, 2008). Fluctuations in the political scene or one-off events can exert a noteworthy effect in equity markets; in the cross correlation of assets; in portfolio allocation and diversification decisions (inter alia: Omar et al. 2016; Asteriou and Siriopoulos, 2003). Events such as elections, governmental changes, political upheavals, civil strife or more violent episodes such as terrorist attacks, affect economic performance and asset markets (inter alia: Guidolin and La Ferrara, 2010; Drakos and Kallandranis, 2015; Gaibulloev and Sandler, 2009). Similarly, armed conflicts, be it intrastate or interstate, or simply geopolitical friction and tension generate significant levels of risk and uncertainty and invariably leave an indelible and traceable mark on global markets (inter alia: Zussman et al. 2008; Choudhry, 2010; Frey and Kucher, 2000, 2001; Schneider and Troeger, 2006). Depending on the type of the event the impact exerted can be short-lived and fade away as time elapses or, it can bring about longer lasting effects and noteworthy shifts in markets influencing portfolio allocation and diversification and the relationship between different markets (inter alia: Pástor and Veronesi, 2013; Kollias et al. 2013a, 2013b; Omar et al. 2016; Aslam and Kang, 2015). Within the thematic focus of this 
growing corpus of empirical studies, this paper sets out to examine the impact of geopolitical risk on the oil-stock covariance, their returns and their variances. Using monthly data for WTI oil index and the S\&P 500 stock index, this study examines whether and to what extent this relationship is affected by geopolitical risk. To this effect, the recently constructed Caldara and Iacoviello (2016) Geopolitical Risk index (hence forth GPR index) is used ${ }^{1}$. To the best of our knowledge, this is the first time that the GPR index is used to examine the effects of geopolitical risk on the stock and oil markets association. The time period of the empirical investigation spans over a century from 1899 to 2016 . The GPR index is introduced in a multivariate Generalised Autoregressive Conditional Heteroskedasticity (GARCH) framework ${ }^{2}$. An unrestricted Vector Autoregressive - GARCH model is employed herein for two main reasons. First, the VAR representation permits the identification of the causality direction between two or more variables without explicitly assuming a specific direction. Second, frequently financial time-series like the stock and oil series used here, present time varying variances affecting the validity of the estimated parameters. For this reason, modelling time-varying conditional variances and covariance is regarded as the suitable approach in such cases. In the following section, the data and methodology are presented. The findings are shown and discussed in section three while section four concludes the paper.

\footnotetext{
${ }^{1}$ Available at https://www2.bc.edu/matteo-iacoviello/gpr.htm.

${ }^{2}$ Multivariate GARCH models have been widely used to study covariance of stocks and bonds (Longin and Solnik 1995; Kim et al. 2006; Connolly et al. 2005, 2007; Yang et al 2009; Kollias et al, 2013b).
} 


\section{Data and methodology}

The relationship between stock markets and oil prices has been extensively examined by a growing body of literature with mixed findings that on balance do not seem to offer any robust and unequivocal empirical evidence (inter alia: Conrad et al. 2014; Nahda and Faff, 2008; Marques and Lopes, 2015; Arouri and Nguyen, 2010; Apergis and Miller, 2009). In broad terms, two predominant strands can be identified in the literature concerning the stock and oil markets nexus. On a theoretical level of argumentation, the relationship between the two markets can either be negative or positive. On the one hand, increases in oil prices invariably lead to higher transportation, production, and heating costs, which can put a drag on corporate earnings. In addition, higher oil prices affect inflation expectations and curtail consumers' discretionary spending. As a consequence, inflationary pressures may lead to upward pressures on interest rates and through this channel affect economic activity and stock price valuations. On the other hand, however, investors may very well associate increasing oil prices with a booming economy. Thus, higher oil prices could reflect stronger business performance with the concomitant impact on stock markets.

In terms of empirical findings, as shown by a number of recent studies, the relationship between oil and stock prices is not stable and varies significantly across firms, sectors, countries and over time (inter alia: Diaz et al. 2016; Joo and Park, 2017; Mohanty et al. 2016; Reboredo and Ugolini, 2016). According to the findings of Gomes \& Chaibi (2014) the volatility spillover effect between oil prices and stock returns appears to be bidirectional in many frontier markets, which is a characteristic that differs from what has been found for developed stock markets where the transmission is usually unidirectional (from oil to stock markets). 
Given the extensive literature on the relationship between oil prices and stock markets, including in the equation of their association the effects of geopolitical risk as quantified by the GPR index, can offer interesting insights on how this relationship is affected by exogenous non-market related factors that emanate from the dynamic and ever evolving international environment that regularly generates tension, friction and confrontation between global actors. As already pointed out above, reported findings show that major exogenous political events such as war, conflict, insurgencies and terrorism have the capacity to bring about noteworthy changes and shifts in equity markets; to influence the relationship between markets and assets, portfolio allocation and diversification, and affect international financial flows such as FDI and international trade (inter alia: Fielding, 2003; Enders et al. 2006; Urquhart and Hudson, 2016; Bandyopadhyay et al. 2014). In other words, the impact of such violent events are not limited to the scenes of their venue and the battlefields with the associated destruction of human and physical capital, but spill-over and have wider economic repercussions since they affect and rattle the routine of normal economic and social life.

Energy and equity markets can be shaken by profound geopolitical changes and the friction and tension that they invariably generate, as well as by major security risk generating episodes. So can their association (Wacziarg, 2012; Omar et al. 2016; Kollias et al. 2013a). This is particularly true for the oil markets given the strategic nature of this commodity and the fact that a large share of the global oil supply is produced in the Middle East. A region that historically has been marred by conflict and wars and has dominated the global agenda for many decades. For example, the data of the Annual Energy Outlook 2016 report by the US Energy Information Administration ${ }^{3}$

\footnotetext{
${ }^{3}$ http://www.eia.gov/outlooks/aeo/.
} 
indicates that the Middle East region (e.g. OPEC members) accounted for almost one third of the global petroleum production in 2015. If to this figure we add the production of other OPEC countries located in geopolitically volatile regions such as North and West Africa, this share almost reaches 37\%. If non-OPEC Middle East and African countries are also added, the total share of petroleum producing countries in these geopolitically volatile and unstable regions of the world exceeds $48 \%$ for 2015 . An advantage of the GPR index constructed by Caldara and Iacoviello (2016) and used here, is that it offers the opportunity to move beyond the examination of how specific events influence markets, and the economy in general as most studies tend to do (inter alia: Fielding, 2003; Frey and Kucher, 2000, 2001; Hudson and Urquhart, 2015; Kollias et al. 2013a, 2013b). The GPR index used herein broadens the perspective of the investigation since it allows for fluctuations in the level of geopolitical risk, and hence for more reliable inferences and better insights into the effects exerted (Caldara and Iacoviello, 2016). For instance, focusing on the Middle East region and the post-War period, the strategic instability that has characterized the area has oscillated from major war outbreaks to relatively less intense conflicts, frictions and political instability in almost all the countries that make up this region. Random examples include the 1956 Suez Canal Crisis, the 1973 Arab-Israeli War (the Yom Kippur War), the 1979 Iranian Revolution, the 1990 Iraqi invasion of Kuwait and the Gulf War (1990-91), the Iraq War, the Gaza Strip conflict, the Egyptian revolution of 1952, numerous cases of civil strife and uprisings such as the various intifadas: Iraq (1952), Bahrain (1965) and the Palestinian ones in 1987-1993 and then 200-05. More recently, one can cite the Arab Spring uprisings that begin in Tunisia in 2010 and spread to other countries including Libya and Egypt, the ongoing Syrian Civil War that erupted in 2011. Furthermore, given the time period covered in the empirical analysis that follows, the paper hopes to shed 
light and offer long-term findings on how and to what extent this relationship is affected by exogenous geopolitical and security shocks. GPR is a monthly index that quantifies the risk associated and generated by events such as tensions and frictions between states, confrontations, armed conflicts and war, terrorist acts. The normal course of international relations is directly and often profoundly affected by such events. As shown, the instability, uncertainty and risk generated in such cases is transited to the economy and impacts economic performance, markets, market agents and sentiment (inter alia: Fielding, 2003; Gaibulloev and Sandler, 2008, 2009; Zussman et al. 2008; Choudhry, 2010; Kollias et al. 2013b; Drakos and Kallandranis; 2015).

The GPR index is derived by counting the occurrence of words related to geopolitical tensions in leading international newspapers (Caldara and Iacoviello, 2016). In the graphical representation of the index (Figure 1), spikes associated for instance with World War I \& II, the collapse of bipolarity, the Kuwait invasion and the Gulf War, the invasion of Iraq are easily identifiable. Undoubtedly, such momentous events were of global importance, having shaped and determined the course of history. Similarly, the impact exerted by one-off events such as the Japanese attack on Pearl Harbor or the 9/11 terrorist attacks - both history shaping incidents - or the Madrid and London bombings in March 2004 and July 2005 have also left an imprint on the index. So has the annexation of Crimea by Russia, the Balkan Wars in early $20^{\text {th }}$ century (October 1912- July 1913), the Russian-Japanese War (February 1904-September 1905), the Falklands War or lesser known events such as the NATO exercise Able Archer in November 1983 that is regarded as one of the occasions that the world came close to a nuclear confrontation during the Cold War era. Hence, it is of interest to know how the two markets in question have reacted to both one-off events such as the 9/11 terrorist attacks, or the Madrid and London bombings as well as events of longer 
duration and of greater geopolitical and history shaping importance such as the two World Wars or the Gulf and Iraqi Wars in more recent years or the annexation of Crimea by Russia. 


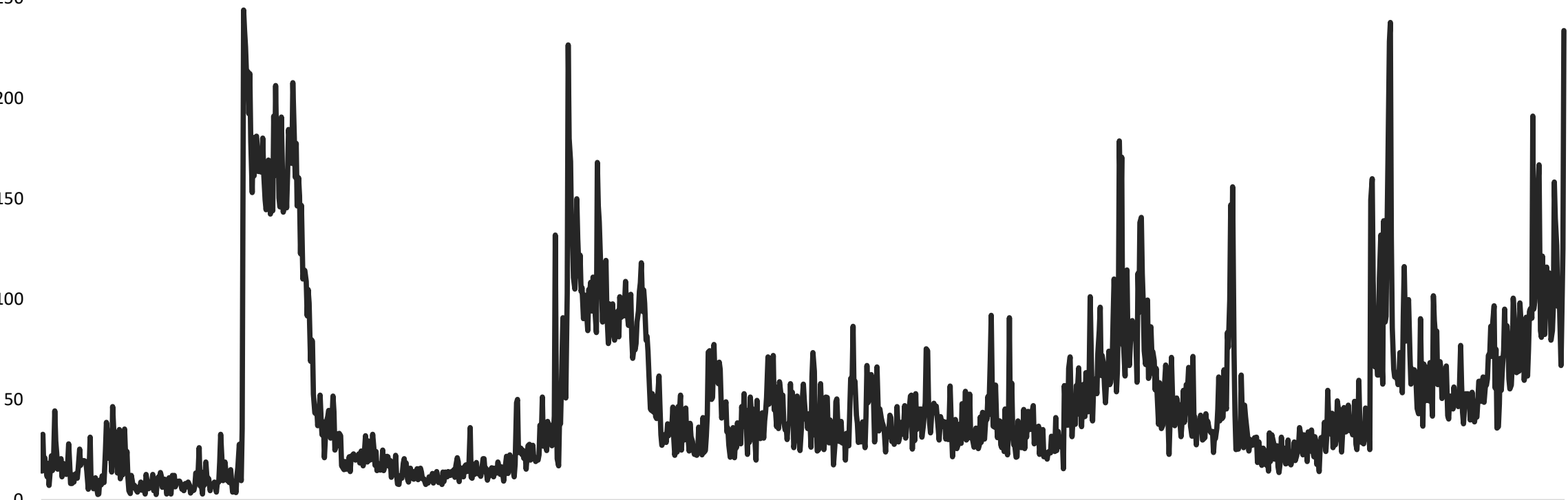

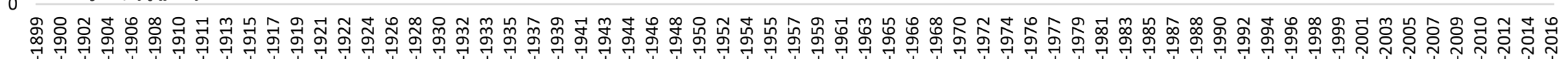

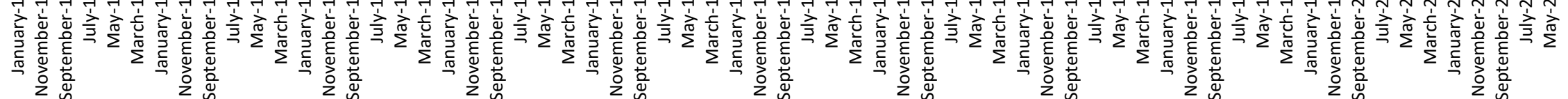


As already noted, the data used in our empirical estimations for the oil and stock markets, consists of monthly observations for the S\&P500 stock index and WTI oil index real returns covering the period January 1899 to August 2016. Note that nominal values of the stock and oil prices are deflated by the Consumer Price Index to obtain the real counterparts of these two series, with data on all these variables derived from the Global Financial Database. In order to examine the impact of the geopolitical events quantified by the GPR index on the oil-stock covariance, their returns and their variances, this index is introduced in a VAR-BEKK-GARCH model. The multivariate GARCH models specify equations for how the variances-covariances move over time. In 1995 one multivariate GARCH formulation was proposed in the literature by Baba, Engle, Kraft and Kroner, widely known as the $B E K K^{4}$ model $^{5}$. In our case the bivariate unrestricted BEKK-GARCH(1,1) model, proposed by Engle and Kroner (1995), is used given its advantage of parsimony and the fact that it addresses the difficulty with $\mathrm{VECH}^{6}$ model of ensuring that the conditional variance-covariance matrix is always positive definite (Kollias et al, 2013a). The joint process governing the two variables is modeled with the bivariate Vector Autoregressive (VAR) unrestricted BEKKGARCH(1,1) model including the geopolitical risk index in the construction of the mean, variances and covariance matrices. More specifically, equation (1) gives the expression for the conditional mean.

\footnotetext{
${ }^{4}$ The BEKK acronym refers to a specific parameteriztion of the multivariate GARCH model developed in Engle and Kroner (1995).

${ }^{5}$ For a more detailed discussion and survey for multivariate GARCH models see among others Bauwens et al. (2006)

${ }^{6}$ Its name is taken by the vectorized representation of the model. Where VECH( ) denotes the operator that stacks the lower triangular portion of a symmetric $\mathrm{N} \times \mathrm{N}$ matrix into an $\mathrm{N}(\mathrm{N}+1) / 2 \times 1$ vector of the corresponding unique elements.
} 


$$
\mathbf{x}_{\mathbf{t}}=\boldsymbol{\gamma}+\boldsymbol{\delta} \sum_{j=1}^{p} \mathbf{x}_{\mathbf{t}-\mathbf{1}}+\boldsymbol{\lambda}_{1} G P R_{\mathbf{t}}+\boldsymbol{\varepsilon}_{\mathbf{t}}
$$

where vector $\mathbf{x}=(R W T I, R S P 500)$ includes the returns in real terms of the WTI oil index (RWTI) and stock (RSP500) markets, respectively. The lag length, defined as " $p$ " is based on Akaike (AIC) criterion. In the first version of our model we include as an exogenous variable the geopolitical risk index in time $\mathrm{t}\left(G P R_{t}\right)$ in the mean and variance-covariance equations. The residual vector $\boldsymbol{\varepsilon}=\left(\varepsilon_{1}, \varepsilon_{2}\right)$ is bivariate and generalized distributed with $\boldsymbol{\varepsilon}_{t} \mid \Phi_{t-1} \sim G E D\left(0, \mathbf{H}_{t}\right)$ and the corresponding conditional variance covariance matrix given by:

$$
\mathbf{H}_{\mathbf{t}}=\left[\begin{array}{l}
h_{11 t} h_{12 t} \\
h_{21 t} h_{22 t}
\end{array}\right]
$$

The second moment will take the following form:

$$
\mathbf{H}_{\mathrm{t}}=\mathbf{C}_{0} \mathbf{C}_{0}^{\prime}+\mathbf{A}^{\prime} \boldsymbol{\varepsilon}_{\mathrm{t}-1} \boldsymbol{\varepsilon}_{\mathrm{t}-1}^{\prime} \mathbf{A}+\mathbf{B}^{\prime} \mathbf{H}_{\mathrm{t}-1} \mathbf{B}+\mathbf{K} \bullet G P R_{t},
$$

where the conditional variance-covariance matrix depends on its past values and on past values of error terms defined on matrix $\boldsymbol{\varepsilon}_{t-1} . C_{0}$ is a $2 \times 2$ matrix, the elements of which are zero above the main diagonal; and $\mathbf{A}, \mathbf{B}$ are $2 \times 2$ matrices. $\mathbf{K}$, is the coefficient matrix for the geopolitical risk index respectively and the operator "•" is the element by element (Hadamard product). More analytically:

$$
\mathbf{H}_{\mathbf{t}}=\left(\begin{array}{ll}
c_{11} & 0 \\
c_{21} & c_{22}
\end{array}\right)\left(\begin{array}{ll}
c_{11} & 0 \\
c_{21} & c_{22}
\end{array}\right)^{\prime}+\left(\begin{array}{ll}
\alpha_{11} & \alpha_{12} \\
\alpha_{21} & \alpha_{22}
\end{array}\right)^{\prime} \boldsymbol{\varepsilon}_{t-1} \boldsymbol{\varepsilon}_{t-1}^{\prime}\left(\begin{array}{ll}
\alpha_{11} & \alpha_{12} \\
\alpha_{21} & \alpha_{22}
\end{array}\right)+\left(\begin{array}{ll}
\beta_{11} & \beta_{12} \\
\beta_{21} & \beta_{22}
\end{array}\right)^{\prime} \mathbf{H}_{\mathbf{t}-1}\left(\begin{array}{ll}
\beta_{11} & \beta_{12} \\
\beta_{21} & \beta_{22}
\end{array}\right)+\mathbf{K} \bullet G P R_{t}
$$

The main advantage of the BEKK-GARCH vs. VECH-GARCH model is that it guarantees by construction that the covariance matrices in the system are positive 
definite. The maximum likelihood is used to jointly estimate the parameters of the mean and the variance equations. In a single equation format the model may be written as follows:

$$
\begin{aligned}
h_{11, t}= & c_{11}^{2}+\alpha_{11}^{2} \varepsilon_{1, t-1}^{2}+2 \alpha_{11} \alpha_{21} \varepsilon_{1, t-1} \varepsilon_{2, t-1}+\alpha_{21}^{2} \varepsilon_{2, t-1}^{2}+\beta_{11}^{2} h_{11, t-1}+2 \beta_{11} \beta_{12} h_{12, t-1} \\
& +\beta_{21}^{2} h_{22, t-1}+\kappa_{11} G P R_{t} \\
h_{12, t}= & c_{11} c_{21}+\alpha_{11} \alpha_{12} \varepsilon_{1, t-1}^{2}+\left(\alpha_{21} \alpha_{12}+\alpha_{11} \alpha_{22}\right) \varepsilon_{1, t-1} \varepsilon_{2, t-1}+\alpha_{21} \alpha_{22} \varepsilon_{2, t-1}^{2}+\beta_{11} \beta_{12} h_{11, t-1} \\
& +\left(\beta_{21} \beta_{12}+\beta_{11} \beta_{22}\right) h_{12, t-1}+\beta_{21} \beta_{22} h_{22, t-1}+\kappa_{12} G P R_{t} \\
h_{22, t}= & c_{21}^{2}+c_{22}^{2}+\alpha_{12}^{2} \varepsilon_{1, t-1}^{2}+2 \alpha_{12} \alpha_{22} \varepsilon_{1, t-1} \varepsilon_{2, t-1}+\alpha_{22}^{2} \varepsilon_{2, t-1}^{2}+\beta_{12}^{2} h_{11, t-1} \\
& +2 \beta_{12} \beta_{22} h_{12, t-1}+\beta_{22}^{2} h_{22, t-1}+\kappa_{22} G P R_{t}
\end{aligned}
$$

In order to investigate further any effect of geopolitical risk with a time lag on stocks and oil and for robustness, we estimate a second version of our model by introducing a time lag on the geopolitical risk index i.e. $G P R_{t-1}$. Therefore, equations (1) and (2) are modified as follows:

$$
\begin{gathered}
\mathbf{x}_{\mathbf{t}}=\boldsymbol{\gamma}+\boldsymbol{\delta} \sum_{j=1}^{p} \mathbf{x}_{\mathbf{t}-\mathbf{1}}+\lambda_{2} G P R_{\mathbf{t}-1}+\boldsymbol{\varepsilon}_{\mathbf{t}} \\
\mathbf{H}_{\mathbf{t}}=\mathbf{C}_{\mathbf{0}} \mathbf{C}_{\mathbf{0}}^{\prime}+\mathbf{A}^{\prime} \boldsymbol{\varepsilon}_{\mathrm{t}-\mathbf{1}} \boldsymbol{\varepsilon}_{\mathrm{t}-\mathbf{1}}^{\prime} \mathbf{A}+\mathbf{B}^{\prime} \mathbf{H}_{\mathrm{t}-\mathbf{1}} \mathbf{B}+\boldsymbol{\Theta} \bullet G P R_{t-1},
\end{gathered}
$$

\section{The findings}

The analysis is based on real oil and stock market returns given that their prices are characterized as I(1) processes. Table A1 in the Appendix presents the descriptive statistics for the return series for both markets. As it can be seen, stock mean returns are positive and higher than oil market returns but not statistically significant in both cases. 
In terms of volatility, the oil market volatility is larger compared to the stock market volatility.

Broadly speaking, the Jarque-Bera values are high and statistically significant. In the stock market the degree of skewness measured in absolute terms is higher compared to oil market. Most return series have some auto covariances as indicated by Ljung-Box statistics, and all of them present autoregressive conditional heteroskedasticity (ARCH) effect, as implied by ARCH LM test. Moreover, the distribution of these is fat-tailed because excess kurtosis is greater than zero. As a result, adopting the VAR(p)-BEKK-GARCH(1,1) model in our analysis seems an appropriate choice in order to take into account any time-varying volatility in clusters. Figure 2 also provides evidence of a time varying volatility for both markets. Worth mentioning is that the oil market volatility in general exceeds the stock market volatility exception being the 1930s crisis (see Figure 3). 
Figure 2: Time evolution of Oil and Stock Returns

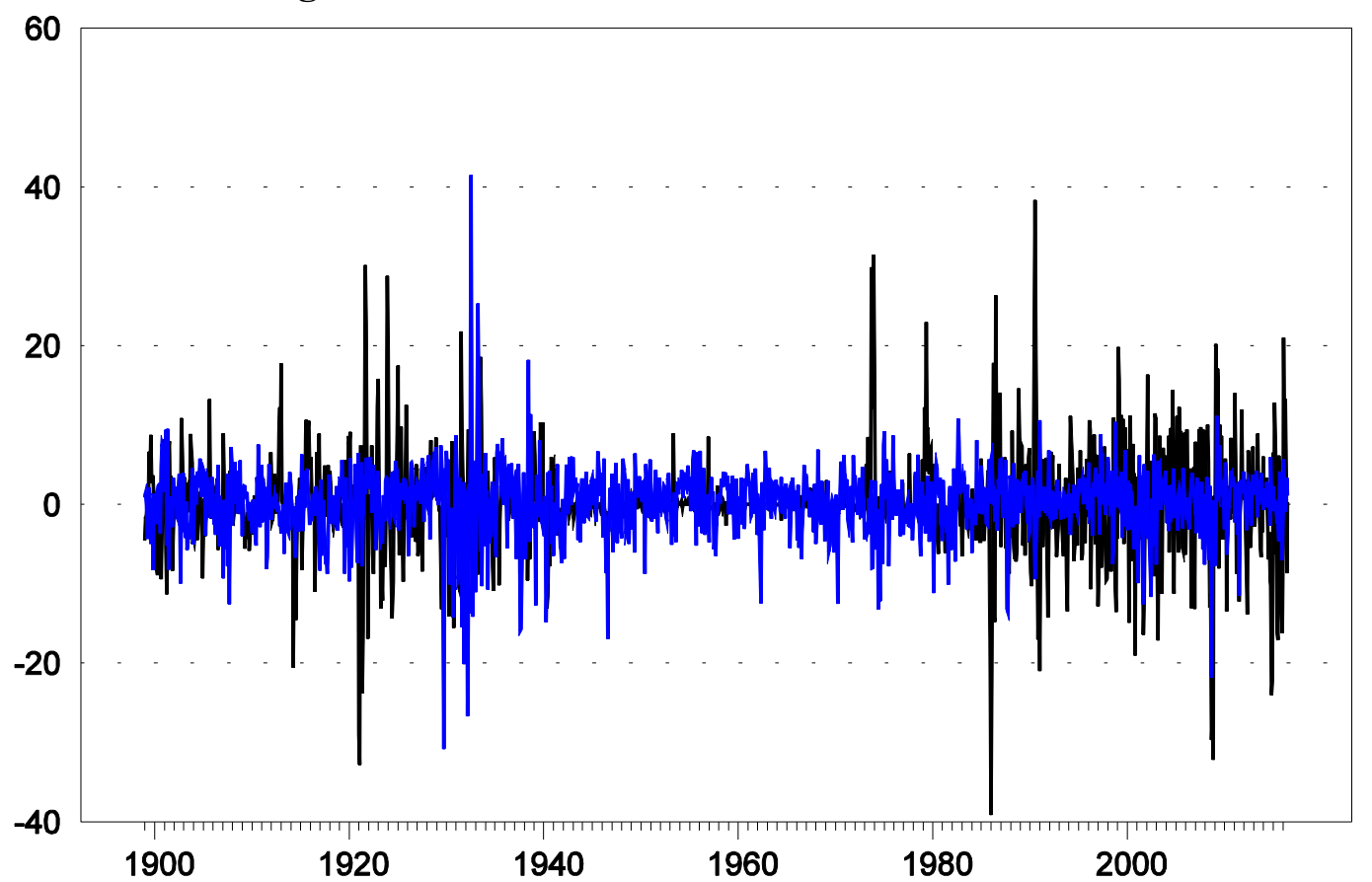

Notes The black line presents the WTI oil Index real returns, while the Blue line indicates the real stock returns.

Figure 3: Conditional Variance of Oil and Stock Returns

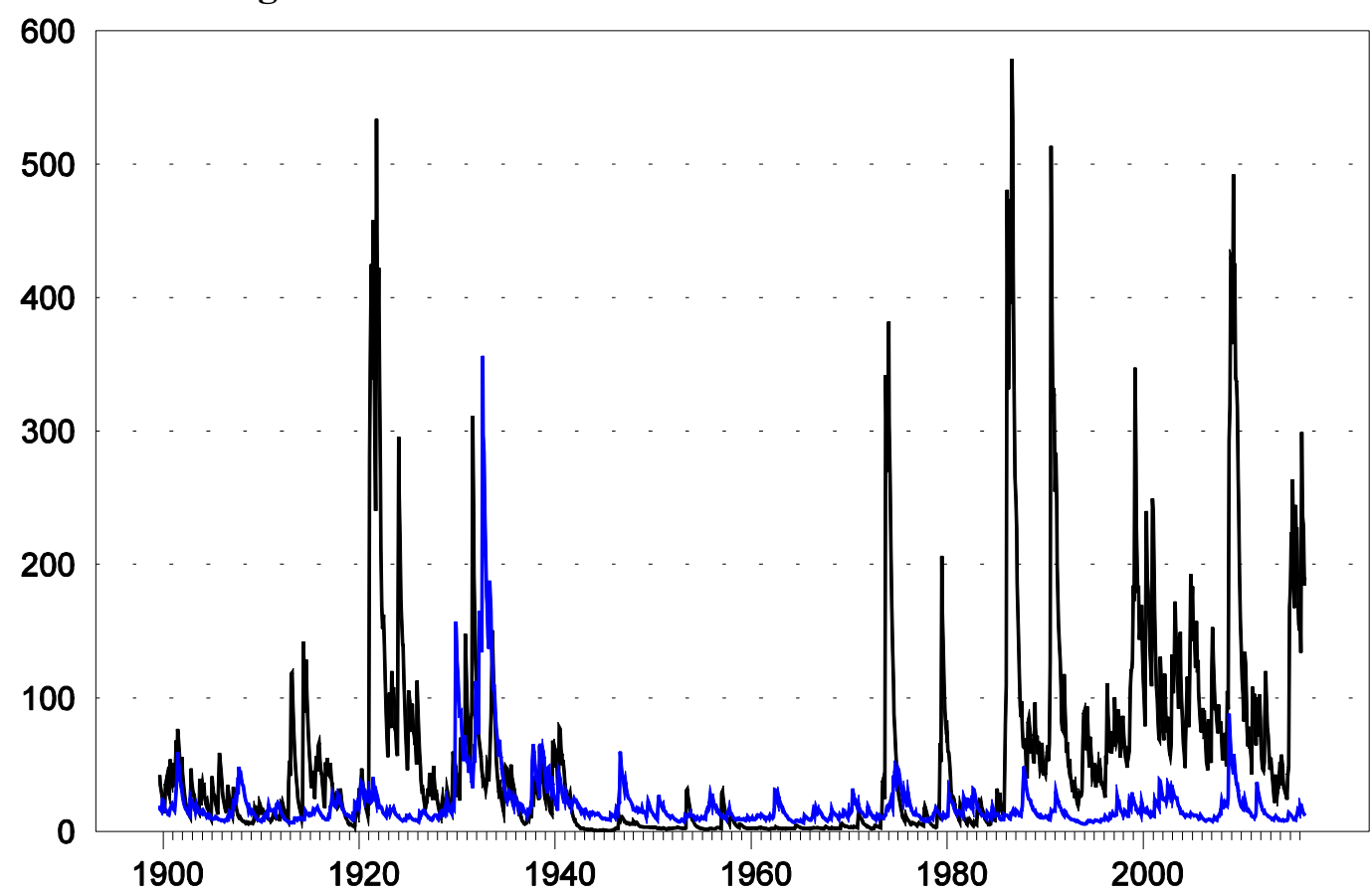

Notes The black line presents the conditional variance of WTI returns, while the Blue line indicates the conditional variance of SP500 stock returns. 
The estimation results for the VAR-unrestricted BEKK-GARCH $(1,1)$ model are presented in Table 1. Column one refers to model one that includes the concomitant geopolitical risk indicator, while column two includes geopolitical risk indicator with one-time lag. The diagnostic tests in the lower part of the table indicate that problems of heteroscedasticity and autocorrelation are not present with the type of the estimated models. Overall, the results of the mean return equations point to a negative statistically significant effect from increased geopolitical risk only in case of oil markets but this effect is present mainly without any time delay. Given that a substantial part of the geopolitical instability and the concomitant risk associated with it historically is generated in petroleum producing regions of the world such as the Middle East and Africa, this finding should not come as a surprise. Many of the spikes in the GPR index (Figure 1) are directly associated with developments and geopolitical risk generating events in such areas. Random examples of war, intra- and interstate conflict, civil strife and violence were cited earlier. In comparison, the absence of a negative and statistically significant effect from increased geopolitical risk in the case of the S\&P500 stock index may be indicating that geopolitical risk is discounted in a more efficient manner by the US market and its agents, suggesting market efficiency when it comes to absorbing and incorporating exogenous shocks. Probing further, it can be seen that the conditional volatility response to geopolitical risk increases. Once again, it could be argued that the latter appears to exert a negative and significant impact only in the case of the oil index but for both volatility models $\left(\mathrm{k}_{11}, \theta_{11}\right)$. Nevertheless, geopolitical risk does not seem to directly affect in any significant and statistically meaningful manner stock market volatility. Overall, our findings indicate that when a geopolitical risk shock occurs, the oil market participants synchronize their trading activity to the same 
direction by reducing returns and volatility is not enough. Something that is not present in case of the stock market index.

Table 1: VAR-BEKK-GARCH(1,1)-in-mean model estimation results

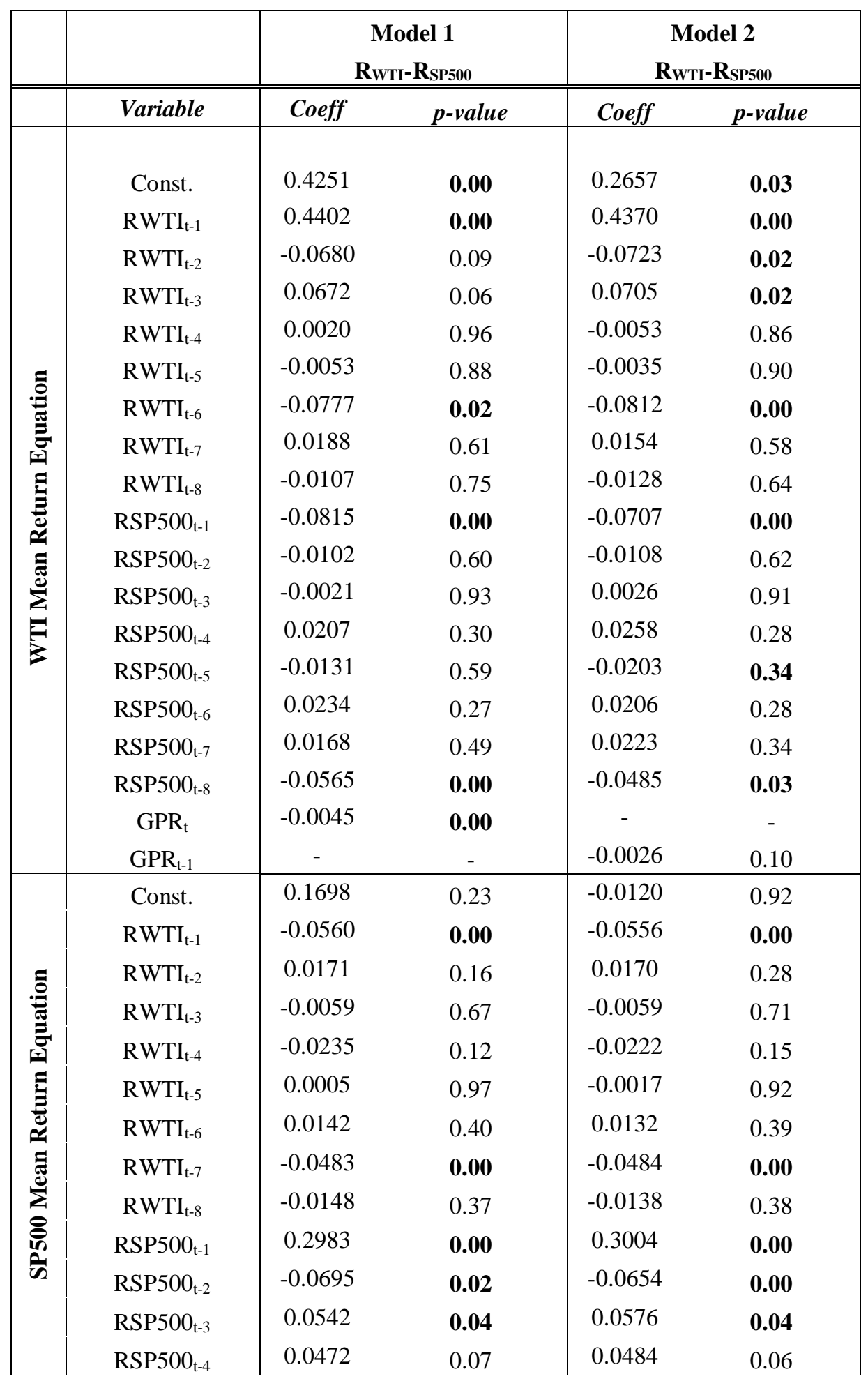




\begin{tabular}{|c|c|c|c|c|c|}
\hline & RSP500t-5 & 0.0311 & 0.26 & 0.0345 & 0.15 \\
\hline & RSP500 ${ }_{t-6}$ & -0.0384 & 0.12 & -0.0354 & 0.10 \\
\hline & RSP500 & 0.0039 & 0.88 & 0.0037 & 0.88 \\
\hline & $\mathrm{RSP} 0 \mathrm{O}_{\mathrm{t}-8}$ & -0.0377 & 0.13 & -0.0343 & 0.16 \\
\hline & $\mathrm{GPR}_{\mathrm{t}}$ & -0.0023 & 0.30 & & \\
\hline & $\mathrm{GPR}_{\mathrm{t}-1}$ & - & - & 0.0014 & 0.46 \\
\hline & $\mathrm{c}_{11}$ & 0.9537 & 0.00 & 1.0629 & 0.00 \\
\hline & $\mathrm{c}_{21}$ & -0.1856 & 0.28 & -0.0845 & 0.59 \\
\hline & $c_{22}$ & 0.8369 & 0.00 & 0.8396 & 0.00 \\
\hline & $\alpha_{11}$ & 0.6003 & 0.00 & 0.5911 & 0.00 \\
\hline$\Xi$ & $\alpha_{12}$ & 0.0195 & 0.21 & 0.0186 & 0.20 \\
\hline 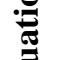 & $\alpha_{21}$ & -0.0333 & 0.18 & -0.0268 & 0.20 \\
\hline تُ & $\alpha_{22}$ & 0.3911 & 0.00 & 0.3910 & 0.00 \\
\hline Ё & $\beta_{11}$ & 0.8854 & 0.00 & 0.8851 & 0.00 \\
\hline$\underset{\pi}{\pi}$ & $\beta_{12}$ & -0.0061 & 0.22 & -0.0061 & 0.22 \\
\hline نَ & $\beta_{21}$ & 0.0225 & 0.04 & 0.0184 & 0.02 \\
\hline 串 & $\beta_{22}$ & 0.9123 & 0.00 & 0.9131 & 0.00 \\
\hline. & $\kappa_{11}$ & -0.0086 & 0.00 & - & - \\
\hline & $\kappa_{12}$ & -0.0039 & 0.11 & - & - \\
\hline & $\kappa_{22}$ & -0.0015 & 0.63 & - & - \\
\hline & $\theta_{11}$ & - & - & -0.0101 & 0.00 \\
\hline & $\theta_{12}$ & - & - & -0.0047 & 0.02 \\
\hline & $\theta_{22}$ & - & - & -0.0014 & 0.51 \\
\hline & GED Parameter & 0.7147 & 0.00 & 0.7153 & 0.00 \\
\hline & $\begin{array}{c}\text { Usable } \\
\text { Observations }\end{array}$ & 1403 & & 1403 & \\
\hline & Log Likelihood & -7557.22 & & -7554.72 & \\
\hline 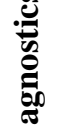 & & $\begin{array}{l}\text { Res. } \\
\text { WTI } \\
\text { eqn. }\end{array}$ & Res. SP500 eqn. & $\begin{array}{l}\text { Res. } \\
\text { WTI } \\
\text { eqn. }\end{array}$ & $\begin{array}{c}\text { Res. SP500 } \\
\text { eqn. }\end{array}$ \\
\hline$\ddot{\theta}$ & $\begin{array}{l}\text { Ljung-Box } \\
Q(12) p \text {-value }\end{array}$ & 0.41 & 0.06 & 0.43 & 0.06 \\
\hline & $\begin{array}{l}\text { McLeod-Li(12) } \\
\text { p-value }\end{array}$ & 0.99 & 0.96 & 0.99 & 0.96 \\
\hline & $\begin{array}{l}\mathrm{ARCH}(4) \text { Test } \\
\text { p-value }\end{array}$ & 0.99 & 0.96 & 0.96 & 0.96 \\
\hline
\end{tabular}

When we turn to the direct effects of geopolitical risk on the time varying conditional covariance between the two markets (Figure 4 presents both the time evolution of geopolitical risk with the conditional correlation), the results indicate a statistical 
significant reduction only in the second model when the geopolitical risk index used here is included with one-time lag (see coefficient $\theta_{12}$ ). This result may be interpreted as implying diversification benefits between stock and oil assets as a result of geopolitical tension and risk. In the case of indirect influences, stock market uncertainty increases the stock-oil covariance through the positive and significant cross term $\beta_{21} \beta_{22}$ in equation (5).

As far as diversification benefits are concerned, during the month of the increased geopolitical uncertainty shock, the significant negative returns in the oil market, in contrast to the weak (half in magnitude) negative stock returns, justifies the inclusion of the latter in a pure oil asset portfolio. Moreover, when looking on time lag effects stock reactions become positive while oil returns are still negative but weaker, implying outperformance of the diversified portfolio. As time pass this shift by investors to stocks in contrast to oil asset explains the statistically significant reduction in their intermarket correlation. 
Figure 4: Geopolitical Risk Index versus Conditional Correlation between Oil and Stock Returns

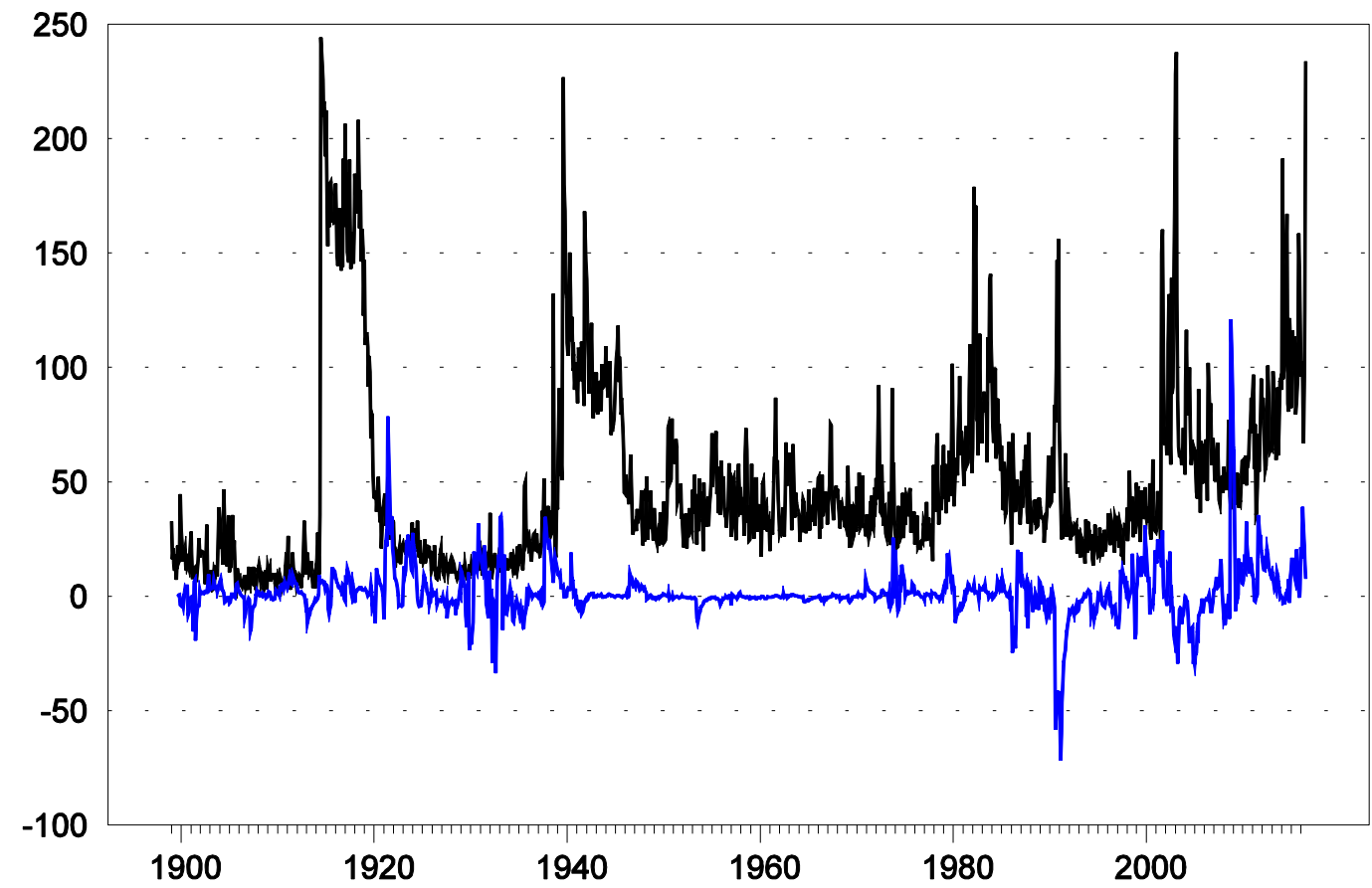

Notes The black line presents the Geopolitical Risk Index, while the Blue line indicates the time varying conditional correlation between Real stock returns and real oil returns.

As far as the other coefficients in the variance equations are concerned, it can be observed that the stock market presents a higher volatility persistence compared to the oil market examined here (compare the $\beta_{11}$ to the $\beta_{22}$ coefficients). Moreover, given that the $\alpha_{11}$ coefficients are higher compared to the $\alpha_{22}$ coefficients it can argued that the impact of geopolitical risk associated news on oil variability is appreciably more substantial (see $\left.\alpha_{11}\right)$ compared to the stock market $\left(\alpha_{22}\right)$ implying different investment reactions in the two markets examined.

\section{CONCLUding REMARKS}

This paper used a recently constructed monthly geopolitical risk index (Caldara and Iacoviello, 2016) to investigate the effects of global tension, friction and conflict 
on the oil-stock markets associations. To this effect two indices were used in the empirical investigation that cover a period longer than a century (1899-2016): the WTI oil index and the S\&P 500 stock index. It did so through a VAR-BEKK-GARCH model that allows the modelling of the mean returns and the variance with the covariance. As many studies have shown, globalised markets respond to major political events. The latter cause traceable effects and indelible imprints affecting such things as the cross correlation between markets and assets, investor sentiment and portfolio allocation. If a broad generalization is attempted based on the findings reported above, then one should highlight the mild but noticeable division between the two market indices. In comparative terms, the oil market index appeared to be more significantly affected by the geopolitical tension index in terms of mean return and variability while the stock market index did not, at least not in a similarly pronounced manner. Moreover, conditional covariance between the two markets was significantly reduced with a time lag in the GPR index.

Acknowledgements: We would like to thank the Editor Brian Lucey and an anonymous referee for helpful comments and constructive suggestions that helped improve the paper. The usual disclaimer applies. 


\section{References}

Apergis, N. and Miller, S.M. (2009) Do structural oil-market shocks affect stock prices? Energy Economics 31, 569-575

Arouri, M. and Nguyen, D.K. (2010) Oil prices, stock markets and portfolio investment: Evidence from sector analysis in Europe over the last decade. Energy Policy 38, $4528-4539$

Aslam, F. and H-G. Kang (2015) How Different Terrorist Attacks Affect Stock Markets, Defence and Peace Economics, 26(6), 634-648

Asteriou, D. and C. Siriopoulos (2003) The role of political instability in stock market development and economic growth: the case of Greece. Economic Notes 29,35574

Bandyopadhyay, S., T. Sandler and J. Younas (2014) Foreign direct investment, aid, and terrorism, Oxford Economic Papers, 66(1), 25-50

Bauwens, L., S. Laurent and J. Rombouts (2006) Multivariate GARCH models: a survey. Journal of Applied Econometrics 21:79-109

Berkman, H., Jacobsen, B., Lee, J.B. (2011) Time-varying rare disaster risk and stock returns. Journal of Financial Economics 101(2), 313-332

Bialkowski, J., Gottschalk, K., Wisniewski, T. (2008) Stock market volatility around national elections. Journal of Banking and Finance 32, 1941-1953

Caldaray, D. and M. Iacoviello (2016) Measuring Geopolitical Risk, https://www2.bc.edu/matteo-iacoviello/gpr_files/GPR_PAPER.pdf

Choudhry, T. (2010) World War II events and the Dow Jones industrial index. Journal of Banking and Finance 34, 1022-1031

Connolly, R., C. Stivers and L. Sun (2005) Stock market uncertainty and the stockbond return relation. Journal of Financial and Quantitative Analysis 40:161-94.

Connolly, R., C. Stivers and L. Sun (2007) Commonality in the time-variation of stockstock and stock-bond return comovements. Journal of Financial Markets 40:192218

Conrad, C., Loch, C. and Ritter, D. (2014) On the macroeconomic determinants of longterm volatilities and correlations in U.S. stock and crude oil markets. Journal of Empirical Finance 29, 26-40 
Diaz, E.M., Molero, J.C., de Gracia, F.P. (2016) Oil price volatility and stock returns in the G7 economies. Energy Economics 54, 417-430

Dimic, D., V. Orlov and V. Piljak (2016) The effect of political risk on currency carry trades Finance Research Letters 19, 75-78

Drakos, K. and C. Kallandranis (2015) A Note on the Effect of Terrorism on Economic Sentiment, Defence and Peace Economics, 26(6), 600-608

Enders, W., Sachsida, A., Sandler, T. (2006) The impact of transnational terrorism on U.S. foreign direct investment, Political Research Quarterly, 59, 517-531

Engle, R. and K. Kroner (1995) Multivariate simultaneous GARCH. Econometric Theory 11:122-50

Fielding, D. (2003) Modelling political instability and economic performance: Israeli investment during the Intifada, Economica 70(277), 159-186

Frey, B. and Kucher, M. (2000) World War II as reflected on capital markets, Economics Letters 69, 187-191

Frey, B. and Kucher, M. (2001) Wars and markets: How bond values reflect the Second World War, Economica 68, 317-333

Gaibulloev, K., Sandler, T., (2008) Growth Consequences of Terrorism in Western Europe, KYKLOS, 61(3), 411-424

Gaibulloev, K., Sandler, T., (2009), The impact of terrorism and conflicts on growth is Asia. Economics and Politics, 21(3), 359-383

Gomes, M., \& Chaibi, A. (2014). Volatility Spillovers Between Oil Prices And Stock Returns: A Focus On Frontier Markets. Journal of Applied Business Research, 30(2), 509

Guidolin, M. and E. La Ferrara (2010) The economic effects of violent conflict: evidence from asset market reactions. Journal of Peace Research 47:671-84

Hudson, R. and A. Urquhart (2015) War and stock markets: The effect of World War Two on the British stock market. International Review of Financial Analysis 40, $166-177$

Joo, Y. and S. Park (2017) Oil prices and stock markets: Does the effect of uncertainty change over time? Energy Economics 61, 42-51

Kaplanski, G. and Levy, H. (2010) Sentiment and stock prices: The case of aviation disasters. Journal of Financial Economics, 95(2), 174-201 
Kim, S-J., F. Moshirian and E. Wu (2006) Evolution of international stock and bond market integration: Influence of the European Monetary Union. Journal of Banking and Finance 30, 1507-34

Kollias, C., Kyrtsou, C. and Papadamou, S. (2013a) The effects of terrorism and war on the oil price-stock index relationship. Energy Economics, 40(6), 743-752

Kollias, C., Papadamou, S., \& Arvanitis, V. (2013b). Does Terrorism Affect the StockBond Covariance? Evidence from European Countries. Southern Economic Journal, 79(4), 832-848

Longin, F. and B. Solnik (1995) Is the correlation in international equity returns constant: 1960-1990? Journal of International Money and Finance 14, 3-26

Marques, S.M. and Lopes, M.C. (2015) Portuguese stock market returns and oil price variations. Applied Economics Letters 22, 515-520

Maghyereh, A.I., Awartani, B., Bouri, E. (2016) The directional volatility connectedness between crude oil and equity markets: new evidence from implied volatility indexes. Energy Economics 57, 78-93

Nandha, M., and Faff, R. (2008) Does oil move equity prices? A global view. Energy Economics 30, 986-997

Omar, A. T. Wisniewski and S. Nolte (2016) Diversifying away the risk of war and cross-border political crisis, Energy Economics, http://dx.doi.org/10.1016/j.eneco.2016.02.015

Urquhart, A. and R. Hudson (2016) Investor sentiment and local bias in extreme circumstances: The case of the Blitz. Research in International Business and Finance $36,340-350$

Pástor, L. and P. Veronesi (2013) Political uncertainty and risk premia. Journal of Financial Economics 110, 520-545

Reboredo, J. and A. Ugolini (2016) Quantile dependence of oil price movements and stock returns, Energy Economics 54, 33-49

Schneider, G. and V. Troeger (2006) War and the world economy, Stock market reactions to international conflicts. Journal of Conflict Resolution 50: 623-45

Wacziarg, R. (2012) The First Law of Petropolitics, Economica 79(316), 641-657

Wolfers, J. and E. Zitzewitz (2009) Using Markets to Inform Policy: The Case of the Iraq War, Economica, 76(302), 225-250 
Yang, J., Y. Zhou and Z. Wang (2009) The stock-bond covariance and macroeconomic conditions: one and a half centuries of evidence. Journal of Banking and Finance $33: 670-80$

Zussman, A., N. Zussman and M. Ø. Nielsen (2008) Asset Market Perspectives on the Israeli-Palestinian Conflict. Economica, 75(297), 84-115 
APPENDIX:

Table A1: Descriptive Statistics

\begin{tabular}{|c|c|c|c|c|c|c|c|c|c|}
\hline & Observations & $\begin{array}{c}\text { Sample } \\
\text { Mean }\end{array}$ & $\begin{array}{c}\text { t-Statistic } \\
\text { (Mean=0, } \\
\text { p-value) }\end{array}$ & $\begin{array}{c}\text { Sample } \\
\text { Variance }\end{array}$ & Skewness & $\begin{array}{c}\text { Kurtosis } \\
\text { (excess) }\end{array}$ & $\begin{array}{l}\text { Jarque- } \\
\text { Bera }\end{array}$ & $\begin{array}{c}\text { Ljung-Box } \\
\text { Test } Q(16) p- \\
\text { value }\end{array}$ & $\begin{array}{c}\operatorname{ARCH}(16) \mathbf{L M} \\
\text { Test p-value }\end{array}$ \\
\hline WTI_Returns & 1411 & 0.0054 & $\begin{array}{l}0.0314 \\
(0.97)\end{array}$ & 36.138 & $\begin{array}{l}-0.044 \\
(0.49)\end{array}$ & $\begin{array}{c}7.767 \\
<0.01 * * *\end{array}$ & $\begin{array}{c}3547.54 \\
<0.01 * * *\end{array}$ & $<0.01 * * *$ & $<0.01 * * *$ \\
\hline $\begin{array}{c}\text { SP500 } \\
\text { Returns }\end{array}$ & 1411 & 0.1634 & $\begin{array}{l}1.425 \\
(0.15) \\
\end{array}$ & 18.541 & $\begin{array}{c}-0.345 \\
<0.01 * * * \\
\end{array}$ & $\begin{array}{c}11.042 \\
<0.01 * * * \\
\end{array}$ & $\begin{array}{c}7196.88 \\
<0.01 * * * \\
\end{array}$ & $<0.01 * * *$ & $<0.01 * * *$ \\
\hline GPR Index & 1411 & 48.691 & $\begin{array}{c}44.901 \\
<0.01 * * *\end{array}$ & 1659.308 & $\begin{array}{c}1.846 \\
<0.01 * * *\end{array}$ & $\begin{array}{c}3.785 \\
<0.01 * * *\end{array}$ & $\begin{array}{c}1644.44 \\
<0.01 * * *\end{array}$ & $<0.01 * * *$ & $<0.01 * * *$ \\
\hline
\end{tabular}


